\title{
Papers
}

\section{Effects of legislation restricting pack sizes of paracetamol and salicylate on self poisoning in the United Kingdom: before and after study}

Keith Hawton, Ellen Townsend, Jonathan Deeks, Louis Appleby, David Gunnell, Olive Bennewith, Jayne Cooper

\begin{abstract}
Objective To evaluate the effects on suicidal behaviour of legislation limiting the size of packs of paracetamol and salicylates sold over the counter. Design Before and after study.

Setting UK population, with detailed monitoring of data from five liver units and seven general hospitals, between September 1996 and September 1999.

Subjects People who died by suicidal or accidental overdose with paracetamol or salicylates or who died of undetermined causes; patients admitted to liver units with hepatic paracetamol poisoning; patients presenting to general hospitals with self poisoning after taking paracetamol or salicylates.

Main outcome measures Mortality from paracetamol or salicylate overdose; numbers of patients referred to liver units or listed for liver transplant; numbers of transplantations; numbers of overdoses and tablets taken; blood concentrations of the drugs; prothrombin times; sales to pharmacies and other outlets of paracetamol and salicylates.

Results Numbers of tablets per pack of paracetamol and salicylates decreased markedly in the year after the change in legislation on 16 September 1998. The annual number of deaths from paracetamol poisoning decreased by $21 \%$ (95\% confidence interval $5 \%$ to $34 \%$ ) and the number from salicylates decreased by $48 \%$ (11\% to $70 \%)$. Liver transplant rates after paracetamol poisoning decreased by $66 \%$ (55\% to $74 \%)$. The rate of non-fatal self poisoning with paracetamol in any form decreased by $11 \%$ (5\% to $16 \%)$, mainly because of a $15 \%(8 \%$ to $21 \%)$ reduction in overdoses of paracetamol in non-compound form. The average number of tablets taken in paracetamol overdoses decreased by $7 \%$ ( $0 \%$ to $12 \%)$, and the proportion involving $>32$ tablets decreased by $17 \%$ ( $4 \%$ to $28 \%$ ). The average number of tablets taken in salicylate overdoses did not decrease, but $34 \%$ fewer (2\% to $56 \%$ ) salicylate overdoses involved $>32$ tablets. After the legislation mean blood concentrations of salicylates after overdose decreased, as did prothrombin times; mean blood concentrations of paracetamol did not change.
\end{abstract}

Legislation on packaging of paracetamol and salicylates (16 September 1998)

- Pharmacies can sell a maximum of 32 tablets per sale (previously there was no limit), although they can still sell up to 100 tablets in justifiable circumstances

- Other retail outlets can sell a maximum of 16 tablets (the previous limit was 24)

- Specific warnings of the dangers of paracetamol overdose are now printed on packets and on leaflets in packets

Conclusion Legislation restricting pack sizes of paracetamol and salicylates in the United Kingdom has had substantial beneficial effects on mortality and morbidity associated with self poisoning using these drugs.

\section{Introduction}

Deliberate self poisoning with non-opiate analgesics, especially paracetamol, is common in the United Kingdom, resulting in a substantial number of deaths each year. ${ }^{1-4}$ The increasing misuse of paracetamol has paralleled a rise in sales, and by implication greater availability, of the drug. ${ }^{5}$ In recent years self poisoning with paracetamol has also been a major cause of liver poisoning: the drug is responsible for approximately half of all cases of liver failure in the United Kingdom. ${ }^{6}$

On 16 September 1998 legislation was introduced in the United Kingdom limiting pack sizes of paracetamol, salicylates, and their compounds sold over the counter (box). ${ }^{7}$ At the same time nearly all preparations became available only in blister packs. The justification for the legislation was that analgesic self poisoning is often highly impulsive and associated with both low suicidal intent and limited knowledge of the possible consequences, ${ }^{89}$ and that the number of cases of overdose might be reduced by limiting availability of the drugs. There is evidence that mortality from paracetamol self poisoning is lower in countries with smaller maximum pack sizes than in the United Kingdom. ${ }^{5}$

We conducted a prospective study to assess the impact of this legislation on mortality from paraceta-
Centre for Suicide Research, University Department of Psychiatry,

Warneford Hospital, Oxford OX3 7JX

Keith Hawton professor of psychiatry Ellen Townsend postdoctoral researcher

ICRF/NHS Centre for Statistics in

Medicine, Institute of Health Sciences, Oxford OX3 7LF

Jonathan Deeks senior medical statistician

School of Psychiatry and Behavioural Sciences, Department of Psychiatry, University of

Manchester,

Withington

Hospital,

Manchester

M20 8LR

Louis Appleby professor of psychiatry Jayne Cooper project manager, Manchester and Salford self harm project

Department of Social Medicine, University of Bristol, Bristol BS8 2PR

David Gunnell senior lecturer in epidemiology and public health medicine Olive Bennewith research associate Correspondence to: K Hawton keith.hawton@ psych.ox.ac.uk

BMJ 2001;322:1-7 
mol and salicylate overdose; cases of liver poisoning after paracetamol overdose, as reflected in numbers of liver transplantations, referrals to liver units, and abnormal liver function tests; number and nature of cases of paracetamol and salicylate overdose; and sales of paracetamol and salicylates.

\section{Methods}

\section{Mortality from overdoses of paracetamol and salicylates}

The Office for National Statistics supplied data on drug related deaths (suicides and accidental self poisoning) and deaths from undetermined cause in England and Wales for September 1996 to September 1999. We included deaths from undetermined cause and accidental poisonings because using suicide verdicts alone to assess overall mortality from suicide is problematic. ${ }^{10}$ We extracted data on deaths of people aged 12 years and over where paracetamol or salicylates were recorded as the only drug involved. We also examined data on deaths where paracetamol or salicylates were part of a compound (excluding co-proxamol) or were taken with another, separate, drug. Data for 1999 are provisional, as some cases are still under coroner's review. The data from 1996 to 1998 indicated that records for $4.5 \%$ of cases were likely to be missing.

\section{Liver transplantation and referrals to liver transplant units}

Data on numbers of admissions after paracetamol overdose, patients listed for liver transplantation, and patients receiving transplants were supplied by five liver units in England for October 1996 to September 1999. In most of these units data were obtained from review of routinely kept clinical records.

\section{Non-fatal self poisoning with paracetamol and salicylates}

Data were collected in Oxford (one hospital), Bristol and Bath (four hospitals), and Manchester (two hospitals) on all presentations with self poisoning between 16 September 1997 and 15 September 1999. Figures for self poisoning with paracetamol, paracetamol compounds (excluding co-proxamol), salicylates, salicylate compounds, and other drugs were extracted. Information was not available for Manchester for all salicylate overdoses. The number of tablets taken in each overdose was recorded; where the number was imprecise we used standard approximations (details available from authors).

In all three centres data were collected on blood paracetamol concentrations and prothrombin times for all paracetamol overdoses where such investigations were requested. Oxford and Bristol also collected data on salicylate concentrations. Where several concentrations were obtained for a patient, we recorded the highest value.

\section{Sales data}

Intercontinental Medical Statistics supplied data for September 1996 to September 1999 on monthly sales of paracetamol and salicylate preparations to pharmacies and other outlets in the United Kingdom. These data cover $97 \%$ of sales to pharmacies, including Boots (but excluding its brand name products). Because manufacturers were given 12 months' notification of the legislation, and rapid changes in pack sizes occurred during that period, sales in the 12 months after the new legislation were compared with those in the penultimate 12 months before legislation. We included only sales of packs of fewer than 100 tablets as we could not determine the proportion of large packs sold on prescription.

\section{Statistical analyses}

Rates of death, non-fatal self poisoning, admission to liver units, listing for liver transplantation, and transplantation were calculated separately for periods of 12 months before and after the new legislation. Exact confidence intervals for these rates were computed using the Poisson distribution. Relative incidence rates are ratios of the rate after the new legislation to the rate before legislation and are expressed as percentage increases or decreases. The data on mortality for January to September 1999 are provisional, as data on some cases still under coroner's review are missing. Similar data from 1996 to 1998 indicate that the number of cases with missing data in this period is likely to be $4.5 \%$ of the figures available to us. An adjustment of $4.5 \%$ was therefore made to the number of deaths after legislation. The proportions of deaths and non-fatal self poisonings attributed to each drug (and to combinations of drugs) before and after the legislation were compared as risk ratios, the changes being expressed as percentage increases or decreases. Confidence intervals and levels of statistical significance were computed using Poisson regression.

Table 1 Numbers of suicides, undetermined deaths, and deaths resulting from accidental poisoning attributable to paracetamol and salicylates among people aged 12 years and over in England and Wales before and after the change in law on packaging*

\begin{tabular}{|c|c|c|c|c|c|c|c|}
\hline \multirow[b]{2}{*}{ Drug } & \multicolumn{3}{|c|}{ No $(\%)$ of deaths } & \multirow[b]{2}{*}{$\begin{array}{c}\% \text { change in incidence } \neq \\
(95 \% \mathrm{CI})\end{array}$} & \multirow[b]{2}{*}{$P$ value } & \multirow[b]{2}{*}{$\begin{array}{l}\% \text { change in proportional } \\
\text { incidence }(95 \% \mathrm{CI})\end{array}$} & \multirow[b]{2}{*}{$P$ value } \\
\hline & $\begin{array}{c}\text { Penultimate } \\
12 \text { months before } \\
\text { change }(n=2255)\end{array}$ & $\begin{array}{l}12 \text { months before } \\
\text { change }(n=2234)\end{array}$ & $\begin{array}{l}12 \text { months after } \\
\text { change }(n=2086) \dagger\end{array}$ & & & & \\
\hline \multicolumn{8}{|l|}{ Paracetamol: } \\
\hline Alone & $203(9.0)$ & $185(8.3)$ & $147(7.0)$ & $-21(-34$ to -5$)$ & 0.01 & $-18(-33$ to -1$)$ & 0.04 \\
\hline With other drugs & $59(2.6)$ & $56(2.5)$ & $56(2.7)$ & 2 (-26 to 39$)$ & 0.9 & 5 (-24 to 44$)$ & 0.8 \\
\hline \multicolumn{8}{|l|}{ Salicylates: } \\
\hline Alone & $35(1.6)$ & $29(1.3)$ & $16(0.8)$ & $-48(-70$ to -11$)$ & 0.02 & $-46(-69$ to -7$)$ & 0.03 \\
\hline With other drugs & $4(0.2)$ & $8(0.4)$ & $3(0.1)$ & -48 (-85 to 81$)$ & 0.3 & $-46(-85$ to 91$)$ & 0.3 \\
\hline Paracetamol and salicylates & $11(0.5)$ & $5(0.2)$ & $9(0.4)$ & 18 (-47 to 163$)$ & 0.7 & 21 (-47 to 174$)$ & 0.6 \\
\hline
\end{tabular}

*16 September 1998

tThese numbers were increased by $4.5 \%$ in the analyses. (See methods section for explanation.)

$\neq$ Comparison of 12 months after the change with the average of the two years before. 
The biochemical data and numbers of tablets taken in each overdose were positively skewed and were summarised using geometric means. Changes were expressed as percentage increases or decreases, their significance being estimated from $t$ tests of logtransformed data. We analysed sales data using $t$ tests without transformation.

Data on transplantations, non-fatal self poisonings, and biochemical concentrations were stratified according to centre (Oxford, Bristol and Bath, and Manchester) and analysed using inverse variance and MantelHaenszel methods. A correction of 0.5 was added to zero counts. All analyses were undertaken using STATA version 6 (StataCorp, College Station, TX).

\section{Results}

Mortality from paracetamol and salicylate overdoses in England and Wales

After the introduction of the new law the proportion of all relevant drug related deaths that were attributable to paracetamol or salicylates on their own decreased significantly (table 1). Compared with the annual rate in the two years before the change, in the next 12 months there were 40 fewer deaths from paracetamol poisoning and 15 fewer from salicylates (after adjustment for missing data). Annual numbers of deaths in which paracetamol or salicylates were taken in combination with other drugs (which may have caused the death) and of deaths in which both paracetamol and salicylates were taken did not change significantly.

\section{Admissions to liver units and numbers of liver transplantations in England}

After the legislation the annual number of admissions with hepatic paracetamol poisoning to liver units declined by $30 \%$ (95\% confidence interval $22 \%$ to $37 \%$ ) compared with the two years before the legislation (fig 1). Significant reductions occurred in all five units (data for one centre have already been published). ${ }^{11}$ Across the five units the annual number of admissions decreased from 310 in the 24 months before the change to 193 in the 12 months after.

Four liver units provided data on listings for liver transplantation. The total number of listings for all these units in the 12 months after the legislation more than halved compared with the annual number for the 24 months before the legislation, and in two of the units the numbers were significantly reduced (fig 2).

After the legislation $66 \%$ fewer patients (55\% to $74 \%$ ) in the five units underwent liver transplantation because of paracetamol poisoning of the liver, compared with the annual number for the two years before the change (fig 3). The reduction in four of the five units was significant: average annual transplantation rates decreased from 25 to 12 per year.

\section{Non-fatal self poisoning with paracetamol and salicylates}

Table 2 shows the number of presentations to seven general hospitals in Bristol and Bath, Oxford, and Manchester after self poisoning with paracetamol or salicylates in the 12 months before and after the legislation. Although overdoses involving paracetamol of any kind as a proportion of the total number of cases of self poisoning did not change, the absolute number decreased significantly by $11 \%$ ( $5 \%$ to $16 \%)$. The proportion of cases in which paracetamol alone was used (the most common type of paracetamol overdose) also decreased significantly (data available for Oxford and Bristol and Bath only). The proportion of overdoses involving paracetamol compounds increased significantly only in Bristol and Bath. Numbers of overdoses involving salicylates, whether alone or in compounds, did not change significantly.

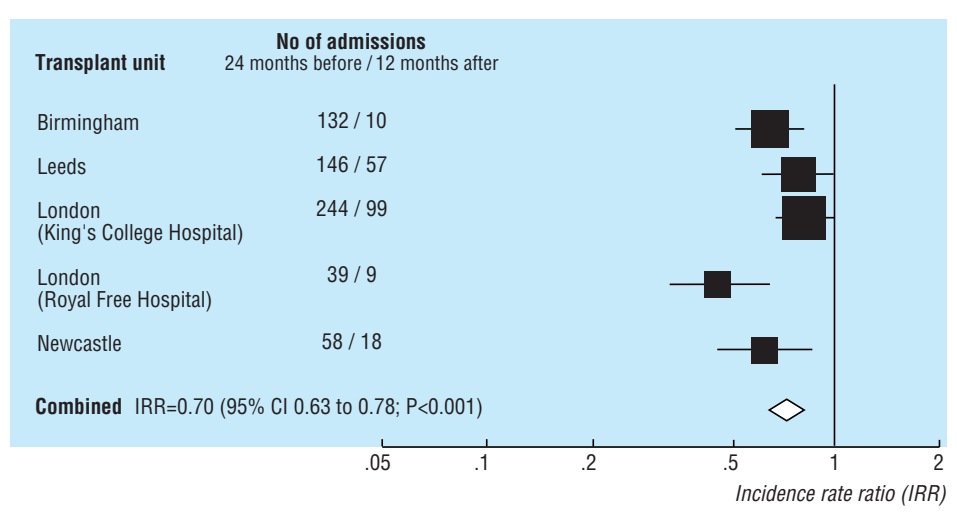

Fig 1 Numbers of patients admitted to liver units with paracetamol poisoning before and after the change in law

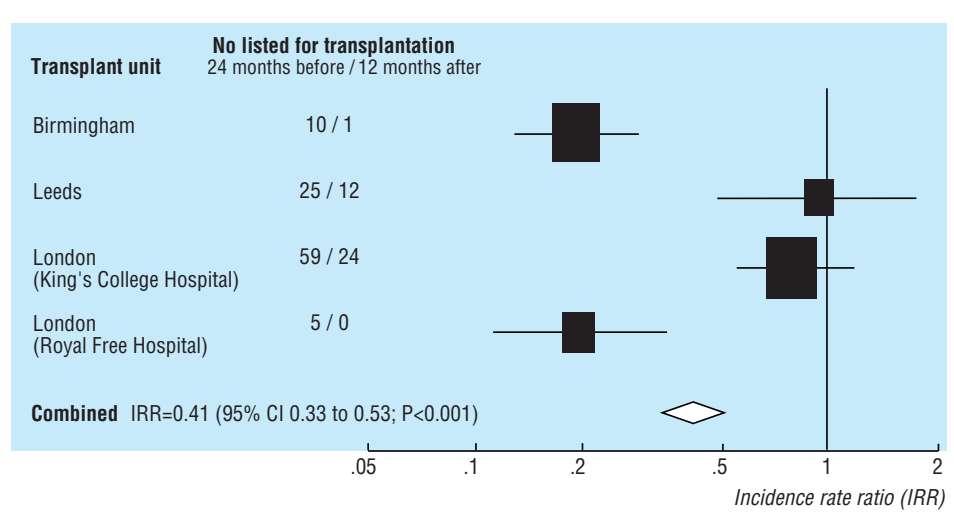

Fig 2 Numbers of patients listed for liver transplantation after paracetamol poisoning before and after the change in law

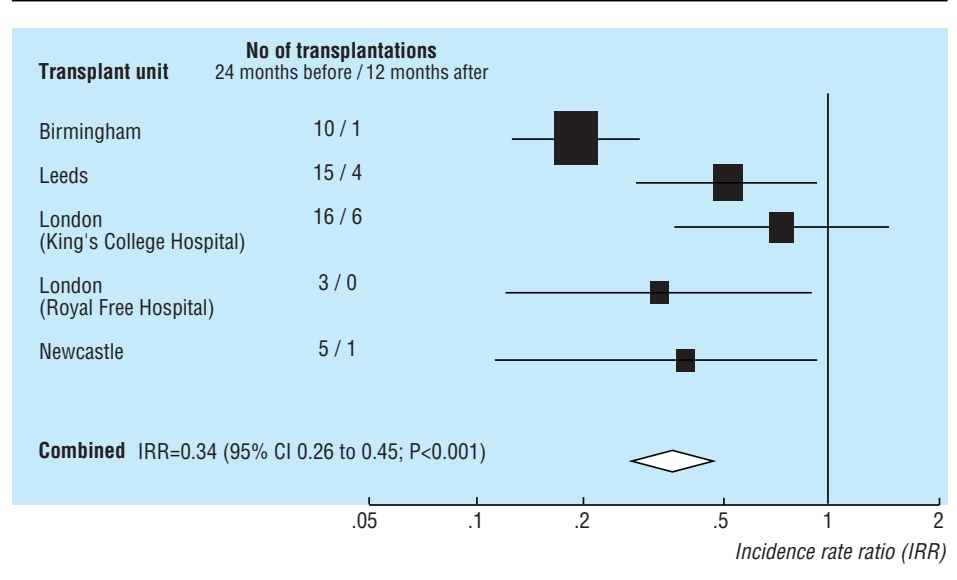

Fig 3 Number of liver transplants undertaken after paracetamol poisoning before and after the change in law 
Table 2 Numbers of presentations to general hospitals in Oxford, Bristol and Bath, and Manchester* after self poisoning with paracetamol or salicylates before and after the change in law on packagingt

\begin{tabular}{|c|c|c|c|c|c|c|}
\hline & \multicolumn{2}{|c|}{$\begin{array}{c}\text { No of cases attributable to drug/Total No of cases of } \\
\text { self poisoning (\%) }\end{array}$} & \multirow{2}{*}{$\begin{array}{l}\% \text { change in number } \\
\qquad(95 \% \mathrm{Cl})\end{array}$} & \multirow[b]{2}{*}{$P$ value } & \multirow{2}{*}{$\begin{array}{l}\% \text { change in proportion } \\
(95 \% \mathrm{CI})\end{array}$} & \multirow[b]{2}{*}{$P$ value } \\
\hline & 12 months before change & 12 months after change & & & & \\
\hline \multicolumn{7}{|l|}{ Single preparations } \\
\hline \multicolumn{7}{|l|}{ Paracetamol alone: } \\
\hline Oxford & $441 / 1250(35.3)$ & $385 / 1218(31.6)$ & $-13(-24$ to 0$)$ & & $-10(-20$ to 0$)$ & \\
\hline Bristol and Bath & $958 / 2550(37.6)$ & $803 / 2369(33.9)$ & $-16(-24$ to -8$)$ & & $-10(-16$ to -3$)$ & \\
\hline Weighted average & & & $-15(-21$ to -8$)$ & $<0.001$ & $-10(-15$ to -4$)$ & 0.001 \\
\hline \multicolumn{7}{|c|}{ Paracetamol compounds: } \\
\hline Oxford & $107 / 1250(8.6)$ & $106 / 1218(8.7)$ & $-1(-25$ to 31$)$ & & 2 (-21 to 32$)$ & \\
\hline Bristol and Bath & $252 / 2550$ (9.9) & $316 / 2369(13.3)$ & 25 (6 to 49$)$ & & 35 (16 to 58$)$ & \\
\hline Weighted average & & & 17 (2 to 35$)$ & 0.02 & 25 (9 to 43$)$ & 0.001 \\
\hline \multicolumn{7}{|c|}{ Paracetamol of any kind: } \\
\hline Oxford & $527 / 1250(42.2)$ & 475/1218 (39.0) & $-10(-21$ to 2$)$ & & $-6(-16$ to 2$)$ & \\
\hline Bristol and Bath & $1145 / 2550$ (44.9) & 1035/2369 (43.7) & $-10(-17$ to -2$)$ & & $-3(-9$ to 4$)$ & \\
\hline Manchester & $514 / 1176(43.7)$ & $446 / 930(48.0)$ & $-13(-24$ to -1$)$ & & $10(0$ to 20$)$ & \\
\hline Weighted average & & & $-11(-16$ to -5$)$ & $<0.001$ & $-1(-6$ to 3$)$ & 0.6 \\
\hline \multicolumn{7}{|l|}{ Salicylates alone: } \\
\hline Oxford & $64 / 1250(5.1)$ & $68 / 1218(5.6)$ & $6(-26$ to 52$)$ & & $9(-22$ to 52$)$ & \\
\hline Bristol and Bath & $148 / 2550(5.8)$ & $129 / 2369(5.4)$ & $-13(-24$ to -1$)$ & & $-6(-25$ to 18$)$ & \\
\hline Weighted average & & & -7 (-23 to 13$)$ & 0.5 & $-2(-18$ to 19$)$ & 0.9 \\
\hline \multicolumn{7}{|l|}{ Salicylate compounds: } \\
\hline Oxford & $63 / 1250(5.0)$ & $49 / 1218(4.0)$ & $-22(-48$ to 15$)$ & & $-20(-45$ to 15$)$ & \\
\hline Bristol and Bath & $117 / 2550(4.6)$ & $113 / 2369(4.8)$ & $-3(-26$ to 26$)$ & & $4(-19$ to 34$)$ & \\
\hline Weighted average & & & $-10(-27 \%$ to $11 \%)$ & 0.3 & $-5(-22$ to 17$)$ & 0.7 \\
\hline \multicolumn{7}{|c|}{ Preparations taken in conjunction with other drugs } \\
\hline \multicolumn{7}{|c|}{ Paracetamol (in any form): } \\
\hline Oxford & $142 / 1250(11.4)$ & $143 / 1218(11.7)$ & 1 (-21 to 28$)$ & & $3(-17$ to 29$)$ & \\
\hline Bristol and Bath & $481 / 2550(18.9)$ & $494 / 2369(20.9)$ & $3(-10$ to 17$)$ & & $11(-1$ to 24$)$ & \\
\hline Manchester & $226 / 1176(19.2)$ & $219 / 930(23.5)$ & $-3(-20$ to 17$)$ & & $23(4$ to 44$)$ & \\
\hline Weighted average & & & $1(-8$ to 11$)$ & 0.9 & $12(3$ to 22$)$ & 0.008 \\
\hline \multicolumn{7}{|c|}{ Salicylates (in any form): } \\
\hline Oxford & $86 / 1250(6.9)$ & $71 / 1218(5.8)$ & $-17(-41$ to 14$)$ & & $-15(-37$ to 15$)$ & \\
\hline Bristol and Bath & $180 / 2550(7.1)$ & $176 / 2369(7.4)$ & $-2(-21$ to 21$)$ & & $5(-14$ to 29$)$ & \\
\hline Weighted average & & & $-7(-22$ to $10 \%)$ & 0.4 & $-1(-17$ to 16$)$ & 0.9 \\
\hline
\end{tabular}

*Not all data were available for Manchester.

†16 September 1998.

Table 2 also shows the numbers of overdoses in which paracetamol or salicylates were taken with other drugs. After the legislation there was a small but significant increase in the proportion in which paracetamol was involved with other drugs, but no sig- nificant change in the absolute number. Numbers of cases in which salicylates were taken with other drugs did not change.

The mean number of tablets taken per paracetamol overdose (data for Oxford and Bristol and Bath)

Table 3 Number of tablets used in cases of self poisoning with paracetamol and salicylates in Oxford and Bristol and Bath before and after the change in law*

\begin{tabular}{|c|c|c|c|c|c|c|c|c|c|c|}
\hline \multirow[b]{2}{*}{ Drug } & \multicolumn{4}{|c|}{ Geometric mean No of tablets per overdose $(95 \% \mathrm{Cl})$} & \multirow[b]{2}{*}{$\begin{array}{c}\% \text { change in mean } \\
\text { No of tablets taken } \\
(95 \% \mathrm{Cl})\end{array}$} & \multirow[b]{2}{*}{$P$ value } & \multicolumn{4}{|c|}{ No $(\%)$ of cases where $>32$ tablets were taken } \\
\hline & $\begin{array}{l}\text { No of } \\
\text { cases }\end{array}$ & $\begin{array}{c}12 \text { months before } \\
\text { change }\end{array}$ & $\begin{array}{l}\text { No of } \\
\text { cases }\end{array}$ & $\begin{array}{l}12 \text { months after } \\
\text { change }\end{array}$ & & & $\begin{array}{l}12 \text { months } \\
\text { before } \\
\text { change }\end{array}$ & $\begin{array}{l}12 \text { months } \\
\text { after change }\end{array}$ & $\begin{array}{c}\% \text { change in proportion } \\
(95 \% \mathrm{Cl})\end{array}$ & $P$ value \\
\hline \multicolumn{11}{|l|}{ Paracetamol } \\
\hline Oxford & 386 & $21.4(19.9$ to 23.1$)$ & 309 & 21.5 (19.7 to 23.4$)$ & $0(-11$ to 13$)$ & & 96 (25) & $85(28)$ & $11(-14$ to 42$)$ & \\
\hline Bristol \& Bath & 886 & 21.7 (20.6 to 22.9$)$ & 713 & 19.7 (18.6 to 20.8$)$ & $-9(-16$ to -2$)$ & & $252(28)$ & $147(21)$ & $-28(-39$ to -13$)$ & \\
\hline Weighted average & & & & & $-7(-12$ to 0$)$ & 0.04 & & & $-17(-28$ to -4$)$ & 0.01 \\
\hline \multicolumn{11}{|c|}{ Paracetamol compounds } \\
\hline Oxford & 82 & $11.4(9.4$ to 13.8$)$ & 77 & 11.7 (9.4 to 14.7$)$ & $3(-23$ to 37$)$ & & $8(10)$ & $12(16)$ & $60(-31$ to 270$)$ & \\
\hline Bristol \& Bath & 214 & $12.9(11.5$ to 14.4$)$ & 273 & 12.5 (11.3 to 13.8$)$ & $-3(-17$ to 12$)$ & & $24(11)$ & $32(12)$ & $5(-36$ to 72$)$ & \\
\hline Weighted average & & & & & $-2(-14$ to 12$)$ & 0.8 & & & $17(-24$ to 79$)$ & 0.5 \\
\hline \multicolumn{11}{|l|}{ Salicylates } \\
\hline Oxford & 56 & $23.3(17.5$ to 30.9$)$ & 59 & 17.7 (14.0 to 22.4$)$ & $-24(-47$ to 9$)$ & & $20(36)$ & $13(22)$ & $-38(-66$ to 12$)$ & \\
\hline Bristol \& Bath & 124 & 20.6 (17.4 to 24.2$)$ & 99 & 20.1 (17.3 to 23.3 ) & $-2(-22$ to 23$)$ & & $31(25)$ & $17(17)$ & $-31(-60$ to 17$)$ & \\
\hline Weighted average & & & & & $-9(-25$ to 10$)$ & 0.3 & & & $-34(-56$ to -2$)$ & 0.04 \\
\hline \multicolumn{11}{|l|}{ Salicylate compounds } \\
\hline Oxford & 60 & 16.8 (13.9 to 20.3 ) & 39 & 13.8 (11.0 to 17.3 ) & $-18(-39$ to 10$)$ & & $8(13)$ & $5(13)$ & $-4(-66$ to 173$)$ & \\
\hline Bristol \& Bath & 105 & 16.2 (13.7 to 19.3 ) & 103 & 15.1 (13.0 to 17.4$)$ & $-7(-26$ to 16$)$ & & $18(17)$ & $9(9)$ & $-49(-76$ to 8$)$ & \\
\hline Weighted average & & & & & $-11(-26$ to 6$)$ & 0.2 & & & $-37(-66$ to 15$)$ & 0.13 \\
\hline
\end{tabular}


Table 4 Quantities (95\% confidence interval) of paracetamol and salicylates sold to pharmacies and other retail outlets in the United Kingdom for sales over the counter before and after the change in law*

\begin{tabular}{|c|c|c|c|c|c|}
\hline Drug & $\begin{array}{l}\text { Penultimate } 12 \text { months } \\
\text { before change }\end{array}$ & 12 months after change & Difference $(95 \%$ CI) & $\%$ change & $P$ value \\
\hline \multicolumn{6}{|l|}{ Paracetamol: } \\
\hline Mean No of tablets per packet sold & 32.6 (26.1 to 39.1$)$ & 24.2 (23.5 to 24.9$)$ & $-8.4(-14.6$ to -2.2$)$ & -26 & 0.01 \\
\hline No of packets (millions) & 280 (1210 to 1351$)$ & 1614 (1 402 to 1825$)$ & 333 (124 to 543) & 26 & 0.003 \\
\hline No of tablets (millions) & 42169 (33 394 to 50945$)$ & 38986 (33974 to 44000$)$ & $-3182(-6340$ to 12705$)$ & -8 & 0.5 \\
\hline \multicolumn{6}{|l|}{ Paracetamol compounds: } \\
\hline Mean No of tablets per packet sold & 39.5 (31.6 to 47.4$)$ & 30.1 (29.5 to 30.6$)$ & $-9.4(-16.8$ to -1.9$)$ & -24 & 0.02 \\
\hline No of packets (millions) & 2032 (1 895 to 2169$)$ & 1502 (1 422 to 1581$)$ & $-530(-680$ to -381$)$ & -26 & $<0.0001$ \\
\hline No of tablets (millions) & 81265 (64 073 to 98456$)$ & 45110 (43049 to 47172$)$ & $-36155(-52469$ to -19840$)$ & -44 & 0.0001 \\
\hline \multicolumn{6}{|l|}{ Salicylates: } \\
\hline Mean No of tablets per packet sold & 56.5 (45.2 to 67.9$)$ & 26.1 (25.5 to 26.6$)$ & $-30.5(-41.2$ to-19.8) & -54 & $<0.0001$ \\
\hline No of packets (millions) & 952 (878 to 1026$)$ & 647 (575 to 720$)$ & $-304(-402$ to -207$)$ & -32 & $<0.0001$ \\
\hline No of tablets (millions) & 54736 (43084 to 66 388) & 16901 (14915 to 18887 ) & $-37835(-48972$ to -26698$)$ & -69 & $<0.0001$ \\
\hline \multicolumn{6}{|l|}{ Salicylate compounds: } \\
\hline Mean No of tablets per packet sold & 29.2 (23.1 to 35.2) & $13.1(12.3$ to 13.8$)$ & $-16.1(-21.8$ to -10.3$)$ & -55 & $<0.0001$ \\
\hline No of packets (millions) & 335 (316 to 354$)$ & 484 (139 to 396) & 150 (64 to 235) & -45 & 0.001 \\
\hline No of tablets (millions) & 9610 (7559 to 11662$)$ & 6233 (5 332 to 7 135) & $-3377(-5488$ to -1266$)$ & -35 & 0.003 \\
\hline \multicolumn{6}{|l|}{ Paracetamol and salicylate compounds: } \\
\hline Mean No of tablets per packet sold & $61.0(48.7$ to 73.2$)$ & $15.3(14.8$ to 15.7$)$ & $-45.7(-57.2$ to -34.2$)$ & -75 & $<0.0001$ \\
\hline No of packets (millions) & 262 (245 to 280$)$ & 1075 (877 to 1273$)$ & 812 (625 to 999) & 310 & $<0.0001$ \\
\hline No of tablets (millions) & 15699 (12 434 to 18964$)$ & $16292(13503$ to 19080$)$ & $592(-3453$ to 4638$)$ & 4 & 0.8 \\
\hline
\end{tabular}

*16 September 1998.

decreased slightly in the 12 months after the legislation compared with the previous 12 months, but the decrease was significant only in Bristol and Bath (table 3). The proportion of overdoses in which more than 32 tablets were taken, whether paracetamol or salicylates, decreased significantly. The numbers of tablets taken in overdoses of paracetamol compounds, salicylates, or salicylate compounds all decreased, though not significantly.

\section{Biochemical data and results of tests of liver function}

The mean highest blood paracetamol concentrations recorded in Oxford, Bristol and Bath, and Manchester did not change after the legislation, but the mean highest prothrombin times decreased slightly $(-2 \%(0 \%$ to $-4 \%)$ ). The mean highest salicylate concentrations recorded in Oxford and Bristol also decreased $(-17 \%$ $(-11 \%$ to $-21 \%))$.

\section{Sales data}

The mean numbers of tablets per pack of paracetamol and salicylates sold to pharmacies in the United Kingdom decreased markedly in the 12 months after the legislation compared with the penultimate 12 months before. There was, however, a compensatory increase in the number of packs sold of paracetamol, such that the total number of tablets of paracetamol sold did not change (table 4). The total numbers of tablets of paracetamol compounds, salicylates, and salicylate compounds sold to pharmacies decreased significantly. The numbers of tablets sold of preparations combining both paracetamol and salicylates did not change significantly.

\section{Discussion}

The legislation introduced in September 1998 to reduce the maximum number of tablets in packs of paracetamol and salicylates and to ensure the inclusion of stronger warnings of the danger of taking too many tablets was followed by significant reductions in mortality and morbidity resulting from self poisoning with these drugs. Although interpreting results from a study with a simple before and after design is problematic, ${ }^{12}$ the evidence for a causal relation between the legislation and the changes in mortality and morbidity is strong, especially because the decrease in the number of cases of self poisoning with paracetamol alone and in the resulting mortality came after several years of successively increasing numbers of paracetamol overdoses and related deaths. ${ }^{12}{ }^{13}$ The effects of the legislation on mortality, numbers of cases of self poisoning, morbidity, and drug sales were consistent for both paracetamol and salicylates.

\section{Methodological issues}

It is important to consider the possibility of incomplete or inconsistently recorded data when interpreting the results of before and after studies. We made an adjustment to account for the incompleteness of mortality data for 1999. However, the degree of undercounting was small and had been consistent over the three previous years. Our investigation of trends in self poisoning was based on routinely collected data from seven hospitals. Although clinicians in these centres were aware of the introduction of the legislation, there is no reason to believe that this would have affected their recording of routine clinical information. Another potential limitation of before and after studies is the difficulty of accounting for underlying trends in the outcomes; analysis based on proportional incidence counters this. We are not aware of any changes in policy on blood testing in cases of overdose during the study period. One liver unit did not provide data for inclusion in the analyses, but there is no reason to expect that the pattern in this centre would have been any different from that in the other centres.

Packs of 100 or more tablets were omitted from the analyses of sales as we were unable to determine what proportion of these were sold over the counter as opposed to being provided on prescription. Since the new legislation, nearly all packs of this size would be 
supplied only on prescription, which suggests that our estimated changes are underestimates.

\section{Mortality and morbidity}

The number of deaths from self poisoning with paracetamol alone went down by 40 from the 12 months before the law change to the 12 months after, and the corresponding figure for salicylates was about 15. The reduction in mortality from paracetamol self poisoning was reflected in reduced morbidity. The reduction in the number of admissions to liver units because of paracetamol poisoning has already been highlighted. ${ }^{11}$ Our analysis of data from five liver units shows that there was an even greater reduction in the number of these admissions that progressed to liver transplantation.

\section{Non-fatal self poisoning}

These trends were also reflected in a reduction in the number and proportion of overdoses in which paracetamol was taken alone, the predominant type of overdose involving paracetamol. The small but significant increase in overdoses in which paracetamol compounds or paracetamol together with other drugs were taken may be a result of the decreased availability of paracetamol and consequent use of other drugs to increase the size of the overdose. There was a small reduction in the mean number of paracetamol tablets taken per overdose, and a somewhat more marked decrease in the number of overdoses in which a large number of tablets was taken. Also, although the maximum blood concentrations of paracetamol in patients in whom measurements were taken did not change overall, there was a small decrease in the proportion of patients with abnormal prothrombin times-a sensitive measure of liver poisoning. ${ }^{14}$

A reduction in the frequency and severity of paracetamol self poisoning after the legislation has been reported in a London hospital. ${ }^{15}$ We also noted a reduction in the number of large overdoses of salicylates and in maximum blood salicylate concentrations.

\section{Sales of paracetamol and salicylates}

Trends in the nature and number of paracetamol and salicylate overdoses and their consequences are compatible with sales data, which showed a marked reduction in the mean number of tablets per pack sold to pharmacies and some other outlets for all relevant preparations in the 12 months after the new legislation compared with the penultimate 12 months before. Although increases in the number of packs sold of paracetamol and paracetamol-salicylate compounds seemed to compensate for these decreases, the net effect would have been a reduction in the maximum number of tablets in households. The sales data cover most but not all relevant products and would reflect sales over the counter.

\section{Conclusion}

The legislation has been relatively successful, in that it was followed by a marked reduction in the number of deaths resulting from overdoses of paracetamol and salicylates and by fewer liver transplantations and reduction in other indices of morbidity associated with paracetamol self poisoning. The results indicate that the main factor was the reduction in the number of tablets per pack. Elsewhere we have shown that

\section{What is already known on this topic}

Paracetamol and salicylate overdoses are very common in the United Kingdom and are associated with high levels of mortality and morbidity

International comparison shows that national mortality from paracetamol overdose may be related to the maximum number of tablets in individual preparations

Legislation to limit the size of packs of paracetamol and salicylates was introduced in the United Kingdom in September 1998

\section{What this study adds}

The number of tablets in packets of paracetamol and salicylate preparations decreased markedly in the 12 months after the legislation

The number of deaths from self poisoning with paracetamol alone and with salicylates alone decreased after the legislation

There was also a decrease in the number of liver transplants and admissions to liver units with hepatic paracetamol poisoning and in the number of overdoses of paracetamol and salicylates in which large numbers of tablets were taken

stronger warnings on labels are unlikely to have much impact. $^{8}$

Since the new legislation, pharmacies and other retail outlets have usually allowed only one pack to be bought per transaction. Although this does not prevent a customer visiting several outlets to amass a large supply of the drugs, the general effect of the legislation is to reduce the maximum number of analgesic tablets available for impulsive self poisoning. An even smaller maximum pack size for pharmacy sales, such as the $8 \mathrm{~g}$ limit in France, might have had a greater impact still. Further monitoring is needed to see if the gains persist and to detect any signs of substitution of other possibly more dangerous drugs in cases of self poisoning.

We thank Sue Kelly, Olivia Christophersen, and Alan Baker (Office for National Statistics); Claire Cuff (Intercontinental Medical Statistics); John McVittie (clinical biochemistry, John Radcliffe Hospital, Oxford); Sue Mulholland (Centre for Suicide Research, Oxford University); the staff of the department of psychological medicine, John Radcliffe Hospital; Paul Thomas and James Osborn (chemical pathology, Bristol Royal Infirmary); Ann Fisher (haematology, Wythenshawe Hospital, Manchester); Tony Cummings (biochemistry, Manchester Royal Infirmary); Julia Wendon (liver unit, King's College Hospital, London); Andrew Burroughs (liver unit, Royal Free Hospital, London); James Neuberger and Damian Dowling (liver unit, Queen Elizabeth Hospital, Birmingham); Mervyn Davies and Helen Aldersley (liver unit, St James's Hospital, Leeds); Oliver James, Martin Prince, and Mark Hudson (liver unit, Freeman Hospital, Newcastle).

Contributors: $\mathrm{KH}$ initiated the study and contributed to the design, interpretation, and reporting. ET coordinated the collection of the data and contributed to the study design, interpretation, and reporting. JD conducted the statistical analyses and contributed to the interpretation and reporting. LA and DG contributed to the design of the study, data collection, interpretation, and reporting. $\mathrm{JC}$ and $\mathrm{OB}$ contributed to 
database design, data collection, and reporting. $\mathrm{KH}$ is guarantor for the study.

Funding: South East Region NHSE Research and Development. KH is also supported by Oxfordshire Mental Healthcare Trust.

Competing interests: None declared.

1 Hawton K, Fagg J, Simkin S, Bale E, Bond A. Trends in deliberate self-harm in Oxford, 1985-1995. Implications for clinical services and the prevention of suicide. Br J Psychiatry 1997;171:556-60.

2 Bialas MC, Reid PG, Beck P, Lazarus JH, Smith P M, Scorer RC. Changing patterns of self-poisoning in a UK health district. $Q J$ Med 1996;89:893-901.

3 Spooner JB, Harvey JG. Paracetamol overdoses-facts not misconceptions. Pharm J 1993; May 22:706-7.

4 Bray GP. Liver failure induced by paracetamol. BMJ 1993;306:157-8.

5 Gunnell D, Hawton K, Murray V, Garnier R, Bismuth C, Fagg J, et al. Use of paracetamol for suicide and non-fatal poisoning in the UK and France: are restrictions on availability justified? J Epidemiol Community Health 1997;51:175-9.

6 O'Grady J. Acute liver failure. Medicine 1999;27:80-2.
7 Committee on Safety of Medicines, Medicines Control Agency. Paracetamol and aspirin. Curr Probl Pharmacovigilance 1997;23:9.

8 Hawton K, Ware C, Mistry H, Hewitt J, Kingsbury S, Roberts D, et al. Paracetamol self-poisoning. Characteristics, prevention and harm reduction. Br J Psychiatry 1996;168:43-8.

9 Hawton K, Ware C, Mistry H, Hewitt J, Kingsbury S, Roberts D, et al. Why patients choose paracetamol for self poisoning and their knowledge of its dangers. BMJ 1995;310:164

10 Charlton J, Kelly S, Dunnell K, Evans B, Jenkins R, Wallis R. Trends in suicide deaths in England and Wales. Popul Trends 1992;69:10-6.

11 Prince MI, Thomas SHL, James OFW, Hudson M. Reduction in incidence of severe paracetamol poisoning. Lancet 2000;355:2047-8.

12 Poulin C. Prevention of paracetamol poisoning. Lancet 2000;355:2010-1.

13 Atcha Z, Majeed A. Paracetamol related deaths in England and Wales, 1993-97. Health Statistics O 2000;7:5-9.

14 Harrison PM, O'Grady J, Keays RT, Alexander GJ, Williams R. Serial prothrombin time as a prognostic indicator in paracetamol induced fulminant hepatic failure. BMJ 1990;301:964-6.

15 Turvill JL, Burroughs AK, Moore KP. Change in occurrence of paracetamol overdose in UK after introduction of blister packs. Lancet 2000;355:2048-9.

(Accepted 8 February 2001) 